\title{
Influência do Período de Cultivo de Panicum maximum (Cultivar Tanzânia) na FitorRemediação de Solo Contaminado COM PICLORAM ${ }^{1}$
}

\author{
Influence of Panicum maximum Cultivation Period on Phytoremediation of Soil Contaminated \\ with Picloram
}

CARMO, M.L. ${ }^{2}$, PROCOPIO, S.O. ${ }^{3}$, PIRES, F.R. ${ }^{4}$, CARGNELUTTI FILHO, A. ${ }^{5}$, BRAZ, G.B.P. ${ }^{6}$, SILVA, W.F.P. ${ }^{6}$, BARROSO, A.L.L. ${ }^{7}$, SILVA, G.P. ${ }^{7}$, CARMO, E.L. ${ }^{2}$, BRAZ, A.J.B.P. ${ }^{7}$ e ASSIS, R.L. ${ }^{7}$

\begin{abstract}
RESUMO - O objetivo deste trabalho foi avaliar a influência do tempo de cultivo de Panicum maximum (cultivar Tanzânia) sobre a fitorremediação de solo contaminado com picloram. O experimento foi conduzido em casa de vegetação no período de setembro de 2006 a fevereiro de 2007. Os fatores foram compostos pela combinação entre quatro períodos de cultivo da espécie vegetal Panicum maximum (cultivar Tanzânia) (0, 60, 80 e 100 dias) e três doses do picloram $\left(0,80\right.$ e $\left.160 \mathrm{~g} \mathrm{ha}^{-1}\right)$, totalizando 12 tratamentos. O delineamento experimental utilizado foi o inteiramente casualizado em esquema fatorial 4 x 3, com quatro repetições. Como substrato utilizaram-se amostras de solo classificado como Latossolo Vermelho eutroférrico. Após o tempo estabelecido de atuação da espécie fitorremediadora, efetuouse a semeadura das espécies bioindicadoras da presença do picloram: tomate e soja. As espécies bioindicadoras demonstraram alta sensibilidade à presença do picloram no solo, sendo inviável o cultivo dessas culturas em áreas contaminadas com esse herbicida sem a execução de algum procedimento remediador. O cultivo prévio de Tanzânia por 60 dias garantiu crescimento inicial satisfatório das plantas de soja e tomate quando a contaminação inicial não foi maior que $80 \mathrm{~g} \mathrm{ha}^{-1}$ de picloram. Acima desse valor, a fitorremediação ocorrida proporcionou menor crescimento das plantas de soja e tomate, sendo necessário maior tempo de descontaminação.
\end{abstract}

Palavras-chave: residual de herbicidas, mimetizadores de auxinas, soja, tomate, descontaminação do solo, sucessão de culturas.

\begin{abstract}
The objective of this study was to evaluate the influence of cultivation time of Panicum maximum ( $c v$. Tanzania) on phyto-remediation of soil contaminated with picloram. The experiment was carried out under greenhouse conditions from September 2006 to February 2007, using euthroferric Red Latosol samples as substrate for plant growth. The experiment was arranged in a completely randomized design, with four replicates, with treatments in a $4 \times 3$ factorial scheme. The treatments comprised twelve combinations of four periods of soil cultivation with the species Panicum maximum (cv. Tanzania) (0, 60, 80 and 100 days) and three doses of picloram (0, 80 and $\left.160 \mathrm{~g} \mathrm{ha}^{-1}\right)$. At the end of each pre-established time of soil cultivation with the phyto-remediating species, seeds of tomato and soybean plants, used as bio-indicators of picloram presence, were sown on soil. The bio-indicators showed high sensitivity to picloram in soil, as their cultivation was not feasible without a prior phyto-remediation procedure. The previous cultivation of Tanzania
\end{abstract}

1 Recebido para publicação em 11.10.2007 e na forma revisada em 27.3.2008.

2 Mestrando do Programa de Pós-Graduação da Fesurv - Universidade de Rio Verde, 75901-970, Rio Verde-GO; ${ }^{3}$ Pesquisador da Embrapa Tabuleiros Costeiros, 49025-040, Aracaju-SE, <procopio@cpatc.embrapa.br>, Bolsista do CNPq. ${ }^{4}$ Professor do Dep.de Ciências da Saúde, Biológicas e Agrárias do Centro Universitário Norte do ES/UFES, 29933-480, São Mateus-ES; ${ }^{5}$ Professor do Dep. de Estatística da UFRGS, 91509-900, Porto Alegre-RS; ${ }^{6}$ Discente de Agronomia da Fesurv - Universidade de Rio Verde; ${ }^{7}$ Professor da Faculdade de Agronomia da Fesurv - Universidade de Rio Verde.

Planta Daninha, Viçosa-MG, v. 26, n. 2, p. 315-322, 2008 
for 60 days ensured a satisfactory initial growth of both soybean and tomato plants when the initial contamination level was lower than $80 \mathrm{~g} \mathrm{ha}^{-1}$ of picloram. Above this dose, phyto-remediation provided by Tanzânia plants provide a lower soybean and tomato plants growth, indicating that a longer period of decontamination is required.

Keywords: carryover, auxin agonists, soybean, tomato, soil decontamination, crop succession.

\section{INTRODUÇÃO}

O manejo químico de plantas daninhas em pastagens é um dos mais utilizados, em razão da praticidade e do baixo custo (Silva et al., 2006). Dentre os herbicidas registrados para pastagens no Brasil, destacam-se as misturas pré-formuladas picloram $+2,4-\mathrm{D}$ e picloram + fluroxypyr (Rodrigues \& Almeida, 2005). Esses herbicidas apresentam período residual longo no solo, podendo causar danos às culturas subseqüentes ou às culturas sensiveis a resíduos desses produtos, quando se utiliza a matéria orgânica proveniente de áreas tratadas com esses herbicidas (Silva et al., 2006). Além disso, a persistência desses produtos no solo pode inviabilizar a renovação de pastagens degradadas quando se utiliza o sistema de integração entre lavoura e pecuária, principalmente se as culturas envolvidas forem dicotiledôneas.

Não obstante sua eficiência, o picloram é um dos herbicidas que maior preocupação desperta do ponto de vista ambiental, pois apresenta longa persistência (Lavy et al., 1996), podendo ser encontrado no solo até três anos após sua aplicação em área total (Deubert \& Corte-Real, 1986). Também, em razão de sua longa persistência no solo, pode permanecer ativo na matéria orgânica proveniente de pastagens tratadas com esse herbicida (Rodrigues \& Almeida, 2005).

O uso do picloram também tem sido questionado, devido à alta solubilidade em água (430 $\mathrm{g} \mathrm{m}^{-3}$ ) e à baixa sorção pela matéria orgânica ou argila, caracterizando-o como herbicida de elevado potencial de lixiviação (Bovey \& Richardson, 1991). Devido à sua elevada mobilidade, o picloram pode resultar na contaminação de águas subterrâneas (Glass \& Edwards, 1974; Bovey et al., 1975; Lavy et al., 1996). Em simulação promovida por Pang et al. (2000), níveis significativos desse herbicida foram recuperados em lençóis freáticos a 22 e $53 \mathrm{~m}$ de profundidade. Em solos tratados com o picloram, Close et al. (1998) mensuraram a ocorrência de lixiviação até a profundidade de 1,3 m, sendo ele detectado 600 dias após a aplicação nas amostras, constatando a persistência e a lixiviabilidade desse herbicida.

A fim de buscar alternativas para utilização de áreas agrícolas com a presença de compostos persistentes e fitotóxicos no solo, tem-se pesquisado com maior ênfase nos últimos anos o emprego de espécies vegetais capazes de remover e/ou degradar xenobióticos no solo (Pires et al., 2003a) e, conseqüentemente, eliminar o risco de carryover.

Anderson et al. (1994), Perkovich et al. (1996), Kruger et al. (1997) e Arthur et al. (2000) comprovaram a eficiência desta técnica, a fitorremediação, com herbicidas, principalmente atrazine, empregando-se Kochia scoparia. Todavia, essa espécie apresenta restrições, por ser de difícil controle (Anderson et al., 1994). É desejável a seleção de espécies que, além de fitorremediarem o contaminante, apresentem fácil controle posterior e, ainda, se prestem como adubos verdes, espécies forrageiras ou plantas de cobertura.

No Brasil, nos últimos cinco anos, diversas pesquisas foram conduzidas, mostrando a viabilidade de utilizar plantas na remediação dos herbicidas tebuthiuron (Pires et al., 2005a,b; 2006) e trifloxysulfuron-sodium (Procópio et al., 2005a,b; 2006; Santos et al., 2004), de elevada persistência em áreas agrícolas. Para esses herbicidas, as espécies de melhor desempenho foram Stizolobium aterrimum (mucuna-preta) e Cannavalia ensiformis (feijão-de-porco).

O objetivo deste trabalho foi avaliar a influência do tempo de cultivo de Panicum maximum (cultivar Tanzânia) sobre a fitorremediação de solo contaminado com o herbicida picloram. 


\section{MATERIAL E MÉTODOS}

O experimento foi conduzido em casa de vegetação da Fesurv - Universidade de Rio Verde, localizada no município de Rio VerdeGO, cujas coordenadas geográficas são: latitude de $17^{\circ} 47^{\prime} 24^{\prime \prime} \mathrm{S}$, longitude de 5056'31" W e altitude de 698 metros. O período de condução do experimento foi de setembro de 2006 a fevereiro de 2007.

Os fatores foram compostos pela combinação entre quatro períodos de cultivo da espécie Panicum maximum (cv. Tanzânia) $(0,60,80$ e 100 dias) e três doses do picloram $(0,80$ e $160 \mathrm{~g} \mathrm{ha}^{-1}$ ), totalizando 12 tratamentos. O delineamento experimental utilizado foi o inteiramente casualizado em esquema fatorial $4 \times 3$, com quatro repetições.

Foram utilizadas amostras de Latossolo Vermelho eutroférrico como substrato para o crescimento das plantas, cuja análise química e física se encontra na Tabela 1. Essas amostras receberam calagem $\left(2 \mathrm{t} \mathrm{ha}^{-1}\right.$ de calcário filler) e adubação de base de $500 \mathrm{~kg} \mathrm{ha}^{-1}$ da fórmula 08-20-08.

Após o preenchimento e umedecimento dos vasos de $8 \mathrm{dm}^{3}$ de capacidade, procedeuse à aplicação do picloram, utilizando-se um pulverizador costal pressurizado com $\mathrm{CO}_{2}$, munido de barra com duas pontas de pulverização TT 110.02 , aplicando volume de calda equivalente a $200 \mathrm{~L} \mathrm{ha}^{-1}$.

Quarenta e oito horas após a aplicação do herbicida, foi realizada a semeadura da espécie fitorremediadora. Dez dias após a emergência das plantas, realizou-se desbaste, deixando- se 10 plantas por vaso. Os vasos foram irrigados duas vezes ao dia, para manutenção da umidade do solo.

Ao término do tempo estabelecido de atuação da espécie fitorremediadora, esta foi dessecada com glyphosate (1.800 $\mathrm{g} \mathrm{ha}^{-1}$ de equivalente ácido), de acordo com os tratamentos. Cinco dias depois, as plantas foram cortadas na altura do coleto, sendo a parte aérea descartada. A seguir, em todos os vasos, amostras de solo foram retiradas e analisadas quimicamente. De posse dos resultados e tendo como base as necessidades da cultura do tomate (Lycopersicum esculentum), procedeu-se à nova adubação de plantio, específica para cada tratamento, a fim de se uniformizar a disponibilidade de nutrientes em cada unidade experimental. Terminada essa etapa, efetuou-se a semeadura de tomate (cultivar Santa Clara) e soja (cultivar Monsoy 6101), espécies bioindicadoras da presença do picloram, distribuindose 10 sementes de cada espécie por vaso. Após a emergência das espécies bioindicadoras, efetuou-se desbaste, deixando três plantas de cada espécie por vaso. Como na etapa anterior, todos os vasos foram irrigados duas vezes ao dia.

Aos 15 e 40 dias após a emergência (DAE) das plantas bioindicadoras, avaliou-se a altura de plantas, utilizando-se escala graduada, tendo como referência o meristema apical. Aos $40 \mathrm{DAE}$, as plantas bioindicadoras foram cortadas rente ao solo, sendo o material vegetal imediatamente colocado em estufa de circulação forçada de ar $\left(70 \pm 2{ }^{\circ} \mathrm{C}\right)$ por 72 horas e pesado em balança analítica, determinando-se a massa seca da parte aérea.

Tabela 1 - Composição físico-química do solo utilizado no experimento. Rio Verde-GO - 2006/2007

\begin{tabular}{|c|c|c|c|c|c|c|c|c|}
\hline \multicolumn{9}{|c|}{ Análise química } \\
\hline MO & $\mathrm{Ca}+\mathrm{Mg}$ & $\mathrm{Ca}$ & $\mathrm{K}$ & $\mathrm{Mg}$ & $\mathrm{Al}$ & $\mathrm{H}+\mathrm{Al}$ & $\mathrm{K}$ & P (Mehlich) \\
\hline $\mathrm{g} \mathrm{kg}^{-1}$ & \multicolumn{6}{|c|}{ - } & \multicolumn{2}{|c|}{------- $\mathrm{mg} \mathrm{dm}^{-3}$} \\
\hline 12,79 & 0,27 & 0,06 & 0,04 & 0,21 & 0,05 & 2,9 & 17 & 0,30 \\
\hline \multicolumn{5}{|c|}{ Dado complementar } & \multicolumn{4}{|c|}{ Análise granulométrica (\%) } \\
\hline $\mathrm{pH}$ & $\mathrm{m}$ & $\mathrm{V}$ & CTC & SB & \multicolumn{4}{|c|}{ Textura $(\%)$} \\
\hline $\mathrm{CaCl}_{2} 0,01 \mathrm{M}$ & $\%$ & $\%$ & \multicolumn{2}{|c|}{------ $\mathrm{cmol}_{\mathrm{c}} \mathrm{dm}^{-3}$------ } & Argila & \multicolumn{2}{|c|}{ Silte } & Areia \\
\hline 4,09 & 13,65 & 9,88 & 3,20 & 0,32 & 56 & \multicolumn{2}{|r|}{15} & 29 \\
\hline
\end{tabular}

*Análises realizadas no Laboratório de Análises de Solo e Folhas da Faculdade de Agronomia da Fesurv - Universidade de Rio Verde, segundo o método descrito pela Empresa Brasileira de Pesquisa Agropecuária - Embrapa (1997). 
Os dados coletados foram submetidos à análise de variância e teste $\mathrm{F}$ a $5 \%$ de significância. A avaliação dos efeitos significativos do período de cultivo da espécie fitorremediadora, dentro de cada dose do herbicida, foi realizada por análise de regressão. Os coeficientes das equações foram testados pelo teste t a $5 \%$ de significância, e os efeitos das doses do picloram, em cada período de cultivo, por meio do teste de Tukey a 5\% de significância.

\section{RESULTADOS E DISCUSSÃO}

A altura das plantas de soja cultivada em solo tratado com picloram, nas doses de 80 e $160 \mathrm{~g} \mathrm{ha}^{-1}$, foi reduzida aos 15 e 40 dias após a emergência (DAE), sem o cultivo prévio de Panicum maximum (cv. Tanzânia) (Figura 1). Esses resultados mostram que a soja é muito sensivel à presença do picloram no solo, o que reforça o cuidado com o plantio dessa leguminosa em áreas onde esse herbicida tenha sido empregado anteriormente. Segundo Wax et al. (1969), a cultura da soja apresenta sensibilidade a quantidades extremamente baixas do picloram no solo. Por outro lado, em avaliação realizada aos 15 e 40 DAE, o cultivo de Tanzânia anterior à semeadura da soja por 60 dias foi suficiente para garantir melhor crescimento das plantas. Observa-se na Figura 1 e na Tabela 2 que, em solo que recebeu a aplicação prévia de $80 \mathrm{~g} \mathrm{ha}^{-1}$ de picloram, o cultivo da forrageira anulou os efeitos fitotóxicos dos resíduos do herbicida (Tabela 2 e Figura 1). Assim, nesse patamar de contaminação, a fitorremediação com plantas de Tanzânia por 60 dias incorre em menor risco de carryover num cultivo subseqüente de soja. Quanto mais rápida for a descontaminação realizada por espécie fitorremediadora, mais rápida será a liberação da área para o cultivo de uma espécie reconhecidamente sensivel ao xenobiótico previamente utilizado, e também menor a probabilidade de esse composto lixiviar no solo e atingir os mananciais subterrâneos de água.

A altura média das plantas de soja aos 40 DAE foi de $42,05 \mathrm{~cm}$ em solo fitorremediado pelo Tanzânia por 60 dias, e de $6,40 \mathrm{~cm}$ em solo não remediado. Não houve diferença estatística na altura de plantas de soja aos 15 ou $40 \mathrm{DAE}$ no solo com aplicação de $80 \mathrm{~g} \mathrm{ha}^{-1} \mathrm{de}$ picloram, na presença das plantas de Tanzânia
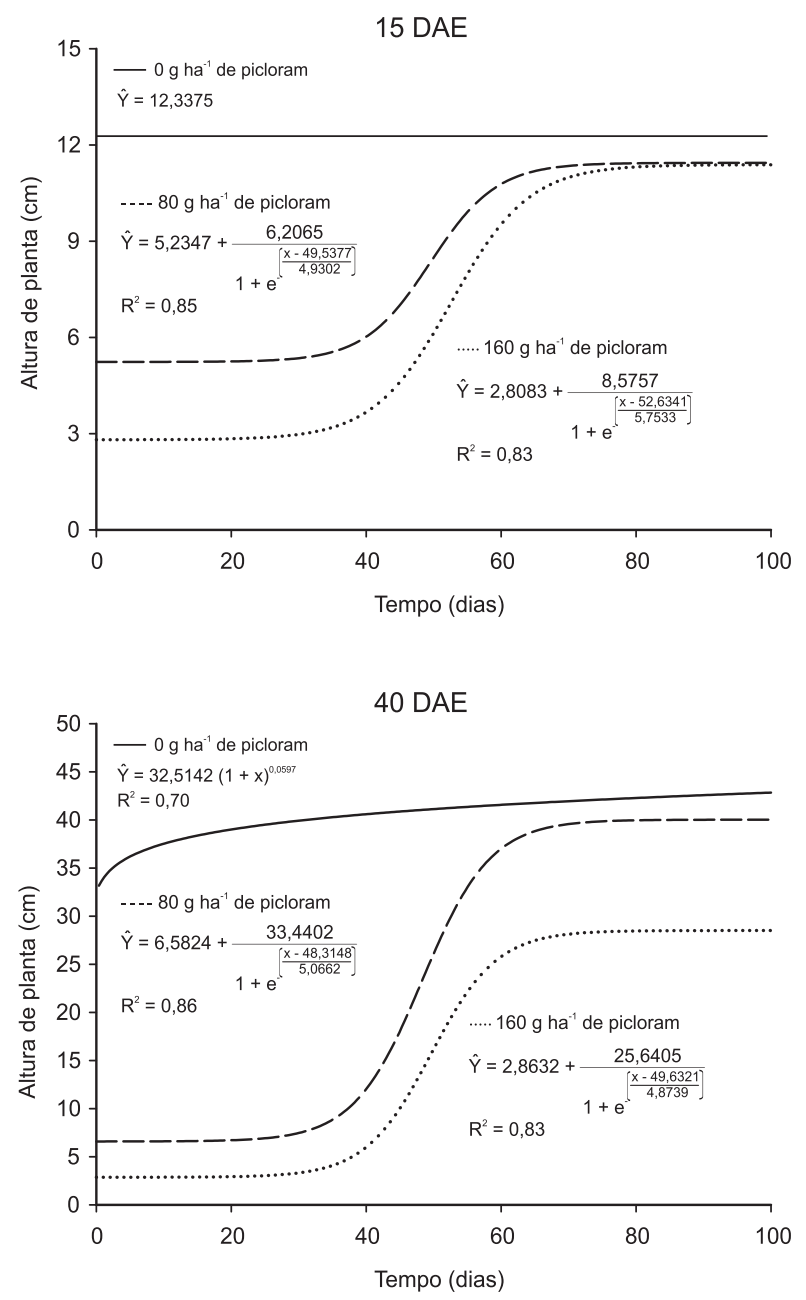

Figura 1 - Altura de plantas de soja aos 15 e 40 dias após a emergência (DAE), semeadas após o cultivo prévio de Panicum maximum (cultivar Tanzânia), em função do período de permanência, em solo contaminado com três níveis do herbicida picloram. Rio Verde, GO - 2006/2007.

por 60,80 ou 100 dias, comparado ao solo que não recebeu aplicação do herbicida (Tabela 2).

Com a aplicação de $160 \mathrm{~g} \mathrm{ha}^{-1}$ de picloram, a fitorremediação realizada pelas plantas de Tanzânia foi significativa, porém sem o mesmo êxito constatado no nível menor de contaminação $\left(80 \mathrm{~g} \mathrm{ha}^{-1}\right)$. A altura das plantas de soja foi maior quando se cultivou o Tanzânia nos tempos de permanência programados $(60,80$ e 100 dias); no entanto, apenas nos cultivos de 80 e 100 dias, aos $15 \mathrm{DAE}$, o porte das plantas de soja não diferiu do tratamento sem herbicida (Tabela 2). Aos 40 DAE, nenhum tratamento de permanência do Tanzânia em solo tratado com $160 \mathrm{~g} \mathrm{ha}^{-1}$ de picloram conseguiu 
Tabela 2 - Altura de plantas de soja semeadas após o cultivo prévio de Panicum maximum (cultivar Tanzânia), em quatro períodos de permanência, em solo contaminado com três níveis do herbicida picloram. Rio Verde-GO - 2006/ 2007

\begin{tabular}{|c|c|c|c|c|}
\hline \multirow{2}{*}{$\begin{array}{c}\text { Dose de } \\
\text { picloram } \\
\left(\mathrm{g} \mathrm{ha}^{-1}\right)\end{array}$} & \multicolumn{5}{|c|}{$\begin{array}{c}\text { Tempo de cultivo de Panicum maximum } \\
\text { (cultivar Tanzânia) (dias) }\end{array}$} \\
\cline { 2 - 5 } & 0 & 60 & 80 & 100 \\
\cline { 2 - 5 } & \multicolumn{4}{|c|}{ Altura de plantas de soja (cm) aos 15 DAE* } \\
\hline 0 & $10,63 \mathrm{a}$ & $13,50 \mathrm{a}$ & $12,90 \mathrm{a}$ & $12,33 \mathrm{a}$ \\
\hline 80 & $5,00 \mathrm{~b}$ & $12,48 \mathrm{a}$ & $11,05 \mathrm{a}$ & $11,80 \mathrm{a}$ \\
\hline 160 & $2,60 \mathrm{~b}$ & $9,58 \mathrm{~b}$ & $10,78 \mathrm{a}$ & $11,88 \mathrm{a}$ \\
\hline & Altura de plantas de soja $(\mathrm{cm})$ aos 40 DAE \\
\hline 0 & $31,93 \mathrm{a}$ & $45,95 \mathrm{a}$ & $41,90 \mathrm{a}$ & $39,40 \mathrm{a}$ \\
\hline 80 & $6,40 \mathrm{~b}$ & $42,05 \mathrm{a}$ & $36,38 \mathrm{ab}$ & $39,98 \mathrm{a}$ \\
\hline 160 & $2,68 \mathrm{~b}$ & $25,73 \mathrm{~b}$ & $29,78 \mathrm{~b}$ & $27,23 \mathrm{~b}$ \\
\hline
\end{tabular}

Médias não seguidas de mesma letra na vertical diferem pelo teste de Tukey a $5 \%$ de probabilidade. ${ }^{*} \mathrm{DAE}=$ dias após a emergência

proporcionar a mesma altura de plantas, em comparação ao solo sem tratamento. Isso mostra que, visando a descontaminação de resíduos no solo superiores a $80 \mathrm{~g} \mathrm{ha}^{1}$ de picloram, faz-se necessário maior tempo de cultivo de Tanzânia como espécie fitorremediadora. Todavia, nos períodos de cultivo de Tanzânia analisados, ocorreu incremento na altura das plantas de $2,68 \mathrm{~cm}$ a mais de $25 \mathrm{~cm}$, aos $40 \mathrm{DAE}$, respectivamente, sem e com cultivo fitorremediador (Tabela 2 e Figura 1).

$\mathrm{O}$ acúmulo de massa seca da parte aérea (MSPA) das plantas de soja acompanhou a mesma tendência dos resultados verificados da altura das plantas dessa espécie. Os resíduos do picloram promoveram queda acentuada do acúmulo de fitomassa das plantas de soja quando não se realizou a fitorremediação do herbicida (Tabela 3). A MSPA média das plantas de soja no tratamento sem herbicida e sem cultivo prévio de Tanzânia foi de $12,70 \mathrm{~g}$, declinando para $3,18 \mathrm{~g}$ quando cultivada em solo tratado com $160 \mathrm{~g} \mathrm{ha}^{-1}$ de picloram sem fitorremediação (Tabela 3). Bovey \& Scifres (1971) reportam que concentrações de picloram de $100 \mathrm{mg} \mathrm{m}^{-3}$ no solo podem causar significativa redução no crescimento de plantas de girassol e Vigna sinensis. Observa-se que, nas condições deste ensaio, em solo não tratado com picloram houve maior acúmulo de MSPA das plantas de soja com cultivo prévio do Tanzânia (Tabela 3 e Figura 2). Isso demonstra o efeito
Tabela 3 - Massa seca da parte aérea de plantas de soja semeadas após o cultivo prévio de Panicum maximum (cultivar Tanzânia), em quatro períodos de permanência, em solo contaminado com três níveis do herbicida picloram. Rio Verde-GO. 2006/2007

\begin{tabular}{|c|c|c|c|c|}
\hline \multirow{2}{*}{$\begin{array}{c}\text { Dose de } \\
\text { picloram } \\
\left(\mathrm{g} \mathrm{ha}^{-1}\right)\end{array}$} & \multicolumn{4}{|c|}{$\begin{array}{c}\text { Tempo de cultivo de Panicum maximum } \\
\text { (cultivar Tanzânia) (dias) }\end{array}$} \\
\cline { 2 - 5 } & 0 & 60 & 80 & 100 \\
\cline { 2 - 5 } & \multicolumn{4}{|c|}{$\begin{array}{c}\text { Massa seca da parte aérea de plantas de soja } \\
(\mathrm{g}) \text { aos } 40 \text { DAE* }\end{array}$} \\
\hline 0 & $12,70 \mathrm{a}$ & $27,88 \mathrm{a}$ & $24,45 \mathrm{a}$ & $23,85 \mathrm{a}$ \\
\hline 80 & $7,23 \mathrm{~b}$ & $25,30 \mathrm{a}$ & $21,02 \mathrm{ab}$ & $21,33 \mathrm{ab}$ \\
\hline 160 & $3,18 \mathrm{~b}$ & $12,77 \mathrm{~b}$ & $19,13 \mathrm{~b}$ & $16,57 \mathrm{~b}$ \\
\hline
\end{tabular}

Médias não seguidas de mesma letra na vertical diferem pelo teste de Tukey a $5 \%$ de probabilidade. ${ }^{*} \mathrm{DAE}=$ dias após a emergência.

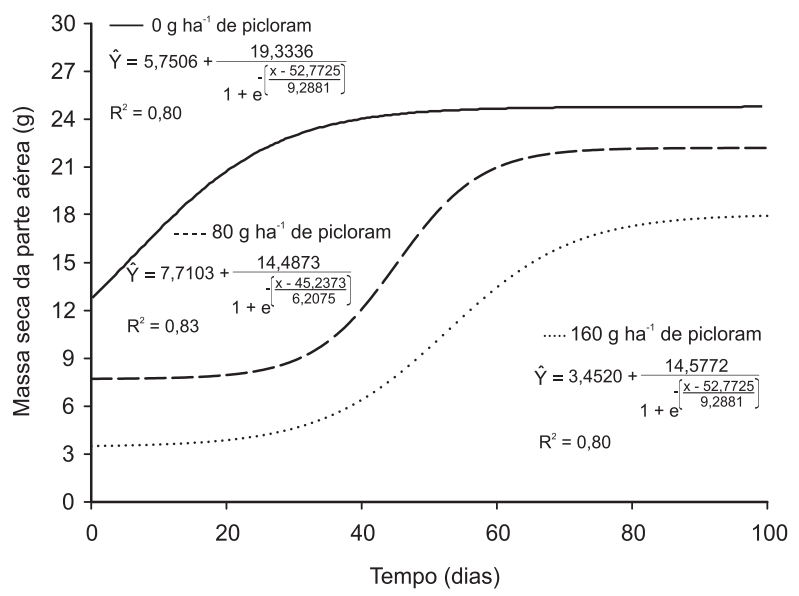

Figura 2 - Massa seca da parte aérea de plantas de soja aos 40 dias após a emergência, semeadas após o cultivo prévio de Panicum maximum (cultivar Tanzânia), em função do período de permanência, em solo contaminado com três níveis do herbicida picloram. Rio Verde-GO - 2006/2007.

benéfico da sucessão dessas espécies, reforçando a possibilidade da utilização do Tanzânia em programas de fitorremediação que envolvam a liberação da área para o plantio de soja. O tempo de permanência das plantas de Tanzânia de 60 dias foi suficiente para proporcionar maior acúmulo de MSPA das plantas de soja, no solo tratado com $80 \mathrm{~g} \mathrm{ha}^{-1}$ de picloram (Tabela 3 e Figura 2). Contudo, no solo tratado com $160 \mathrm{~g} \mathrm{ha}^{-1}$, a MSPA das plantas de soja foi reduzida significativamente, mesmo com a fitorremediação, em todos os períodos de permanência avaliados (Tabela 3 e Figura 2). Observa-se também que, em solo 
tratado com $160 \mathrm{~g} \mathrm{ha}^{-1}$ de picloram, o melhor resultado da fitorremediação foi obtido a partir do tempo de cultivo de 80 dias (Figura 2). Nesse tempo, houve aumento da MSPA média das plantas de soja de 3,18 g, no tratamento sem cultivo, para 19,13 g, com cultivo do Tanzânia por 80 dias. Estudos iniciais realizados por Ferreira et al. (2006) e Silva et al. (2006) apontaram a espécie Brachiaria brizantha como potencialmente remediadora do herbicida picloram.

O tomate também mostrou ser uma planta bioindicadora da presença do picloram no solo, pois ocorreu redução significativa da altura das plantas, quando cultivadas em solo contaminado com o herbicida e sem cultivo fitorremediador com Tanzânia. Essa redução na altura das plantas foi proporcional ao nivel do picloram no solo. Aos $40 \mathrm{DAE}$, a altura média observada nas plantas de tomate que cresceram em solo sem resíduos do herbicida e sem o cultivo de Tanzânia foi de $41,05 \mathrm{~cm}$, enquanto as plantas cultivadas em solo tratado com $160 \mathrm{~g} \mathrm{ha}^{-1}$ de picloram alcançaram a altura média de 2,33 cm (Tabela 4). De acordo com Chang (1969), as técnicas que envolvem bioensaios são eficientes e podem ser utilizadas na estimativa dos niveis de picloram em solos. Isso foi constatado quando se empregaram plantas de feijão (Phaseolus vulgaris) (Merkle et al., 1967) e de girassol (Hang et al.,

Tabela 4 - Altura de plantas de tomate semeadas após o cultivo prévio de Panicum maximum (cultivar Tanzânia), em quatro períodos de permanência, em solo contaminado com três níveis do herbicida picloram. Rio Verde-GO - 2006/2007

\begin{tabular}{|c|c|c|c|c|}
\hline \multirow{3}{*}{$\begin{array}{c}\text { Dose de } \\
\text { picloram } \\
\left(\mathrm{g} \mathrm{ha}^{-1}\right)\end{array}$} & \multicolumn{5}{|c|}{$\begin{array}{c}\text { Tempo de cultivo de Panicum maximum } \\
\text { (cultivar Tanzânia) (dias) }\end{array}$} \\
\cline { 2 - 5 } & 0 & 60 & 80 & 100 \\
\cline { 2 - 5 } & \multicolumn{5}{|c}{$\begin{array}{c}\text { Altura de plantas de tomate }(\mathrm{cm}) \\
\text { aos } 15 \text { DAE* }\end{array}$} \\
\hline 0 & $7,78 \mathrm{a}$ & $8,33 \mathrm{a}$ & $10,75 \mathrm{a}$ & $10,63 \mathrm{a}$ \\
\hline 80 & $5,95 \mathrm{ab}$ & $7,93 \mathrm{a}$ & $9,23 \mathrm{a}$ & $9,80 \mathrm{a}$ \\
\hline 160 & $2,50 \mathrm{~b}$ & $8,60 \mathrm{a}$ & $9,08 \mathrm{a}$ & $10,48 \mathrm{a}$ \\
\hline & Altura de plantas de tomate $(\mathrm{cm})$ aos $40 \mathrm{DAE}$ \\
\hline 0 & $41,05 \mathrm{a}$ & $37,30 \mathrm{a}$ & $40,08 \mathrm{a}$ & $43,00 \mathrm{a}$ \\
\hline 80 & $20,55 \mathrm{~b}$ & $37,55 \mathrm{a}$ & $31,48 \mathrm{ab}$ & $35,63 \mathrm{ab}$ \\
\hline 160 & $2,33 \mathrm{c}$ & $36,48 \mathrm{a}$ & $27,88 \mathrm{~b}$ & $30,05 \mathrm{~b}$ \\
\hline
\end{tabular}

Médias não seguidas de mesma letra na vertical diferem pelo teste de Tukey a $5 \%$ de probabilidade. ${ }^{*} \mathrm{DAE}=$ dias após a emergência.
1996) para indicar a presença de picloram no solo. De maneira semelhante, Scifres et al. (1972) relatam que plantas de feijão e girassol podem exibir sintomas de intoxicação quando cultivadas em solos que contêm menos de $10 \mathrm{ppb}$ de picloram.

Aos 15 DAE, observou-se que todos os tratamentos com Tanzânia garantiram o pleno crescimento das plantas de tomate, independentemente da dose aplicada do picloram e do tempo de fitorremediação (Tabela 4); todavia, a partir de 80 dias foi verificada maior altura das plantas de tomate (Figura 3). Aos $40 \mathrm{DAE}$, observa-se que 60 dias de atuação das plantas de Tanzânia foi suficiente para que as plantas de tomate mantivessem o seu porte, mesmo com a aplicação de $160 \mathrm{~g} \mathrm{ha}^{-1}$ de picloram ao solo (Figura 3). Com a fitorremediação, a altura
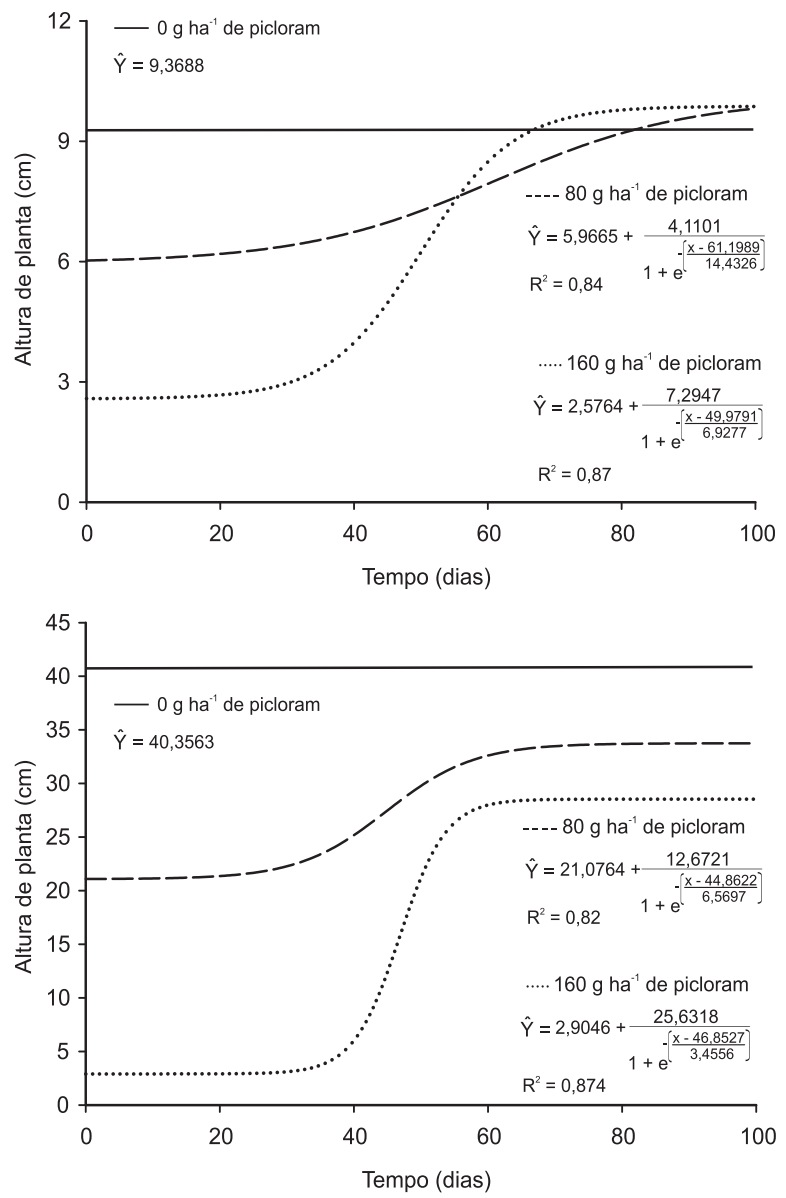

Figura 3 - Altura de plantas de tomate aos 15 e 40 dias após a emergência (DAE), semeadas após o cultivo prévio de Panicum maximum (cultivar Tanzânia), em função do período de permanência, em solo contaminado com três níveis do herbicida picloram. Rio Verde, GO - 2006/2007. 
média das plantas de tomate foi incrementada de $2,33 \mathrm{~cm}$, no tratamento sem fitorremediação, para $36,48 \mathrm{~cm}$, quando as plantas de Tanzânia foram cultivadas por 60 dias (Tabela 4). Observou-se também significativa redução no porte das plantas de tomate nas doses de $80 \mathrm{e}$ $160 \mathrm{~g} \mathrm{ha}^{-1}$ de picloram aos $40 \mathrm{DAE}$, em comparação aos $15 \mathrm{DAE}$, constatada pelas diferenças estatísticas entre os tratamentos (Tabela 4 e Figura 3). Esse comportamento é semelhante ao observado por Pires et al. (2003b) e, provavelmente, se deve à maior ação fitotóxica do composto herbicida absorvido ao longo do periodo de crescimento da planta no solo contaminado.

Foi observado decréscimo significativo da MSPA das plantas de tomate cultivadas em solo com resíduos de picloram, em comparação ao solo não tratado. Sem aplicação do herbicida, o valor médio de MSPA foi de 22,93 g, sendo de 9,85 e 1,60 g, respectivamente, nos solos tratados com 80 e $160 \mathrm{~g} \mathrm{ha}^{-1}$ de picloram (Tabela 5). A fitorremediação por 60 dias com o Tanzânia reduziu o decréscimo da MSPA das plantas de tomate em solo tratado com $80 \mathrm{~g} \mathrm{ha}^{-1}$ de picloram. No entanto, com a aplicação de $160 \mathrm{~g} \mathrm{ha}^{-1}$ de picloram, os acúmulos de MSPA das plantas de tomate foram sempre estatisticamente inferiores em todos os periodos de cultivo do Tanzânia, em comparação ao solo não tratado (Tabela 5 e Figura 4). Como já discutido anteriormente, a descontaminação de resíduos superiores a $80 \mathrm{~g}^{\mathrm{ha}^{-1}}$ de picloram no solo necessita de maior tempo de cultivo de Tanzânia como espécie fitorremediadora. Des-

Tabela 5 - Massa seca da parte aérea de plantas de tomate semeadas após o cultivo prévio de Panicum maximum (cultivar Tanzânia), em quatro períodos de permanência, em solo contaminado com três níveis do herbicida picloram. Rio Verde-GO - 2006/2007

\begin{tabular}{|c|c|c|c|c|}
\hline \multirow{2}{*}{$\begin{array}{c}\text { Dose de } \\
\text { picloram } \\
\left(\mathrm{g} \mathrm{ha}^{-1}\right)\end{array}$} & \multicolumn{4}{|c|}{$\begin{array}{c}\text { Tempo de cultivo de Panicum maximum } \\
\text { (cultivar Tanzânia) (dias) }\end{array}$} \\
\cline { 2 - 5 } & 0 & 60 & 80 & 100 \\
\cline { 2 - 5 } & \multicolumn{5}{|c|}{$\begin{array}{c}\text { Massa seca da parte aérea de plantas de } \\
\text { tomate }(\mathrm{g}) \text { aos } 40 \text { DAE* }\end{array}$} \\
\hline 0 & $22,93 \mathrm{a}$ & $18,43 \mathrm{a}$ & $21,30 \mathrm{a}$ & $20,39 \mathrm{a}$ \\
\hline 80 & $9,85 \mathrm{~b}$ & $19,30 \mathrm{a}$ & $16,67 \mathrm{ab}$ & $16,98 \mathrm{a}$ \\
\hline 160 & $1,60 \mathrm{~b}$ & $13,88 \mathrm{~b}$ & $12,08 \mathrm{~b}$ & $12,28 \mathrm{~b}$ \\
\hline
\end{tabular}

Médias não seguidas de mesma letra na vertical diferem pelo teste de Tukey a $5 \%$ de probabilidade. ${ }^{*} \mathrm{DAE}=$ dias após a emergência.

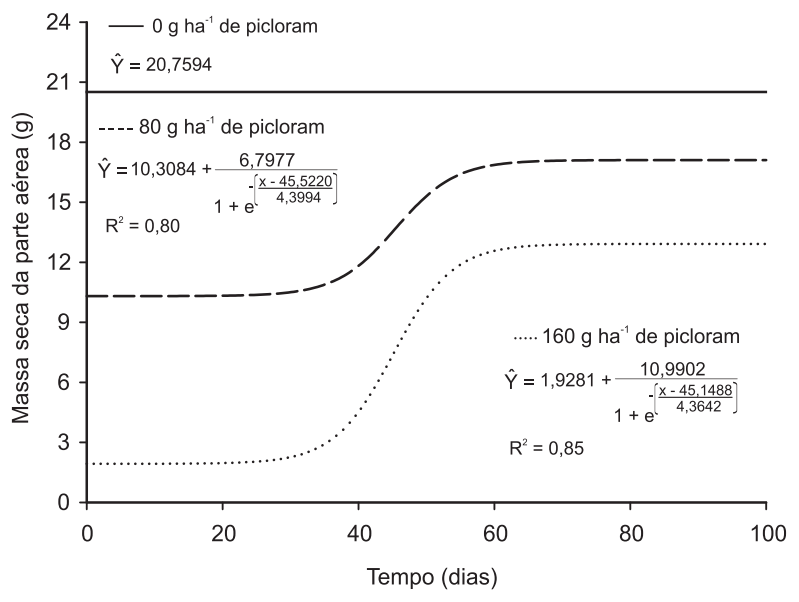

Figura 4 - Massa seca da parte aérea de plantas de tomate aos 40 dias após a emergência, semeadas após o cultivo prévio de Panicum maximum (cultivar Tanzânia), em função do período de permanência, em solo contaminado com três níveis do herbicida picloram. Rio Verde, GO - 2006/2007.

sa forma, diminui-se o risco de carryover e possibilita-se melhor acúmulo de fitomassa das plantas de tomate.

Tanto a soja como o tomate demonstraram alta sensibilidade a resíduos do picloram no solo. Isso torna inviável o cultivo dessas culturas em áreas contaminadas com esse herbicida sem a execução de algum procedimento remediador, sob o risco de perda total da área cultivada. O cultivo prévio de Tanzânia por 60 dias, em solos com características físicas e químicas semelhantes às do utilizado neste estudo, pode garantir crescimento satisfatório de plantas de soja e tomate em ambiente com resíduos de picloram em torno de $80 \mathrm{~g} \mathrm{ha}^{-1}$. Contudo, em maiores concentrações do contaminante, a fitorremediação realizada pelas plantas de Tanzânia não proporcionou bom crescimento das plantas de soja e tomate, sendo necessária continuidade no processo de descontaminação.

\section{LITERATURA CITADA}

ANDERSON, T. A.; KRUGER, E. L.; COATS, J. R. Enhanced degradation of a mixture of three herbicides in the rhizosphere of a herbicide-tolerant plant. Chemosphere, v. 28, n. 8, p. 1551-1557, 1994.

ARTHUR, E. L. et al. Degradation of an atrazine and metolachlor herbicide mixture in pesticide -contaminated soils from two agrochemical dealerships in Iowa. Water, Air, Soil Poll., v. 119, n. 1/4, p. 75-90, 2000. 
BOVEY, R. W. et al. Occurence of 2,4,5-T and picloram in surface runoff water in the Blacklands of Texas. J. Environ. Qual., v. 4, n. 1, p. 103-106, 1975

BOVEY, R. W.; RICHARDSON, C. W. Dissipation of clopyralid and picloram in soil and seep flow in the blacklands of Texas. J. Environ. Qual., v. 20, n. 3, p. 528531,1991 .

BOVEY, R. W.; SCIFRES, S. J. Residual characteristics of picloram in grassland ecosystems. Weslaco: Texas Agricultural Experiment Station, 1971. v. B. 1111 p.

CHANG, H. H. Extraction and colorimetric of picloram in soil. J. Agric. Food Chem., v. 17, n. 6, p. 1174-1177, 1969.

CLOSE, M. E. et al. Leaching of picloram, atrazine and simazine through two New Zealand soils. Geoderma, v. 84, n. 1/3, p. 46-63, 1998.

DEUBERT, K. H.; CORTE-REAL, I. Soil residues of picloram and triclopyr after selective foliar application on utility rights-of-way. J. Arboric., v. 12, p. 269-272, 1986.

EMPRESA BRASILEIRA DE PESQUISA AGROPECUÁRIA - EMBRAPA. Centro Nacional de Pesquisa de Solos. Manual de métodos de análise de solo. 2.ed. Rio de Janeiro: 1997. 212 p

FERREIRA, L. R. et al. Seleção de espécies com potencial de remediação de solos contaminados com os herbicidas triclopyr e 2,4-D + picloram. In: CONGRESSO BRASILEIRO DA CIÊNCIA DAS PLANTAS DANINHAS, 25., 2006, Brasília. Anais... Brasília: 2006. p. 228.

GLASS, B. L.; EDWARDS, W. M. Picloram in lysimeter runoff and percolation water. B. Environ. Contam.

Toxicol., v. 11, n. 2, p. 109-112, 1974.

HANG, S. B.; FERREIRO, E. A.; BUSSETTI, S. G. Movilidad y adsorcion-desorcion de picloram, dicamba e imazaquin. Invest. Agr. Prod. Protec. Vegetales, v. 11, n. 2, p. 345-361, 1996.

KRUGER, E. L. et al. Atrazine degradation in pesticidecontaminated soils: Phytoremediation potential. In: KRUGER, E. L. et al. Phytoremediation of soil and water contaminants. Washington: American Chemical Society, 1997. p. 54-64.

LAVY, T. L. et al. Long-term in situ leaching and degradation of six herbicides aged in subsoils. J.Environ. Qual., v. 25, n. 6, p. 1268-1279, 1996.

MERKLE, M. G.; BOVEY, R. W.; DAVIS, F. S. Factors affecting the persistence of picloram in soil. Agron. J., v. 59, p. 413-415, 1967.

PANG, L. P. et al. Simulation of picloram, atrazine and simazine leaching through two New Zealand soils and into groundwater using HYDRUS-2D. J. Contam. Hydrol. v. 44, n. 1, p. $19-46,2000$.
PERKOVICH, B. S. et al. Enhanced mineralization of [ $\left[{ }^{14} \mathrm{C}\right]$ atrazine in Kochia scoparia rhizosferic soil from a pesticidecontaminated site. Pestic. Sci., v. 46, n. 4, p. 391-396, 1996

PIRES, F. R. et al. Adubos verdes na fitorremediação de solos contaminados com o herbicida tebuthiuron. Caatinga, v. 19, n. 1, p. $92-97,2006$

PIRES, F. R. et al. Inferências sobre a atividade rizosférica de espécies com potencial para fitorremediação do herbicida tebuthiuron. R. Bras. Ci. Solo, v. 9, n. 4, p. 627-634, 2005a.

PIRES, F. R. et al. Fitorremediação de solos contaminados com tebuthiuron utilizando-se espécies cultivadas para adubação verde. Planta Daninha, v. 23, n. 4, p. 711-717, 2005b.

PIRES, F. R. et al. Fitorremediação de solos contaminados por herbicidas. Planta Daninha, v. 21, n. 2, p. 335-341, 2003a.

PIRES, F. R. et al. Seleção de plantas com potencial para fitorremediação de tebuthiuron. Planta Daninha, v. 21, n. 3, p. $451-458,2003 b$.

PROCÓPIO, S. O. et al. Fitorremediação de solo contaminado com trifloxysulfuron-sodium por diferentes densidades populacionais de feijão-de-porco (Canavalia ensiformis (L). DC.). Ci. Agrotecnol., v. 30, p. 444-449, 2006.

PROCÓPIO, S. O. et al. Fitorremediação de solo contaminado com trifloxysulfuron sodium por mucuna-preta (Stizolobium aterrimum). Planta Daninha, v. 23, n. 4, p. 719-724, 2005a.

PROCÓPIO, S. O. et al. Potencial de espécies vegetais para a remediação do herbicida trifloxysulfuron-sodium. Planta Daninha, v. 23, n. 1, p. 9-16, 2005 b.

RODRIGUES, B. N.; ALMEIDA, F. S. Guia de herbicidas. 5.ed. Londrina: Grafmarke, 2005. 591 p.

SANTOS, J. B. et al. Fitorremediação do herbicida trifloxysulfuron-sodium. Planta Daninha, v. 22, n. 2, p. 223-330, 2004

SCIFRES, C. J.; BOVEY, R. W.; MERKLE, M. G. Variation in bioassay attributes as quantitative indices of picloram in soils. Weed Res., v. 12, n. 1, p. 58-64, 1972.

SILVA, L. L. et al. Seleção de espécies tolerantes aos herbicidas triclopyr e 2,4-D + picloram. In: CONGRESSO BRASILEIRO DA CIÊNCIA DAS PLANTAS DANINHAS, 25., 2006, Brasília. Anais... Brasília: 2006. p. 230 .

WAX, L. M.; KNUTH, L. A.; SLIFE, F. W. Response of soybeans to 2,4-D, dicamba and picloram. Weed Sci., v. 17, n. 3, p. 388-393, 1969. 